Article

\title{
Visualization and Understanding of Traffic Flow and Congestion in India
}

\author{
Tsutomu Tsuboi ${ }^{1,}$ * \\ 1 Nagoya Electric Works Co. Ltd. 1; t_tsuboi@nagoya-denki.co.jp \\ * Correspondence: e-mail@e-mail.com; Tel.: +81-52-443-1111
}

\begin{abstract}
This study focuses on traffic condition analysis, especially in under developing country India and makes more visible of traffic flow by using traffic flow theory in order to understand real traffic condition. India is one of rapid economic growing countries and large market with second largest population 1.3 billion in 2018. On the other hand, there are social issues such as environment air pollution and global warming by traffic $\mathrm{CO} 2$ emission of transportation. This kind of condition is not only in India, but in other South East Asia and Africa in future. From recent more than onemonth traffic observation in a typical major city Ahmedabad in Gujarat state, which has about 8 million population and industrialized city. In terms of traffic data collection, 14 CCTV cameras are used in the city. Based on multiple traffic cameras monitoring, author found the unique traffic flow characteristics and compares traffic flow theory. In this study, it is described what is key parameters to show real traffic congestion condition and how these congestion occurs.
\end{abstract}

Keywords: traffic flow analysis; traffic congestion; fundamental traffic flow characteristics;

\section{Introduction}

The global warming and greenhouse effect becomes issue for a while since 1970s including CO2 emission. In terms of CO2 emission, transportation takes $14 \%$ in world-wide and 6.86 Giga tons in 2010 in Figure 1 [1]. In terms of India situation about CO2 emission and number of vehicle transportation between 1994 and 2007 [2], each volume of CO2 emission becomes double and number of vehicles becomes triple in Figure 2.

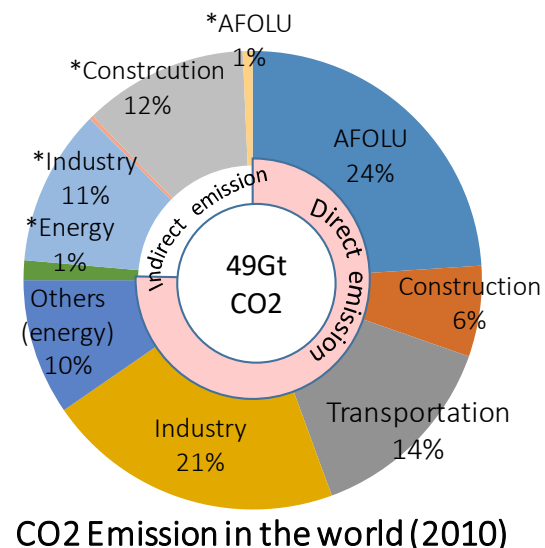

Figure 1. CO2 Emission in the World (2010) (AFOLU: agriculture, forestry and other land use) 


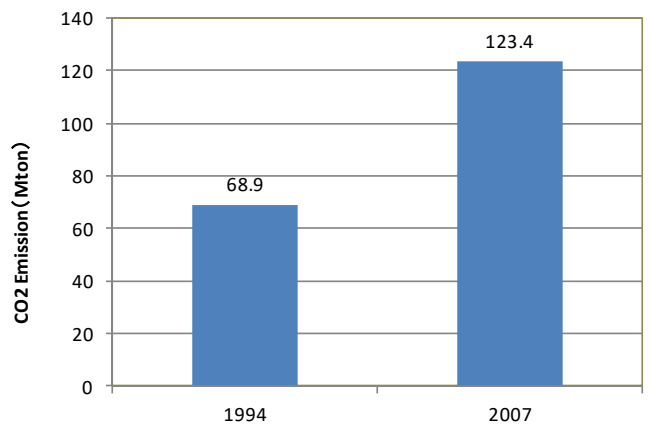

(a) CO2 Emission in Road Transportation

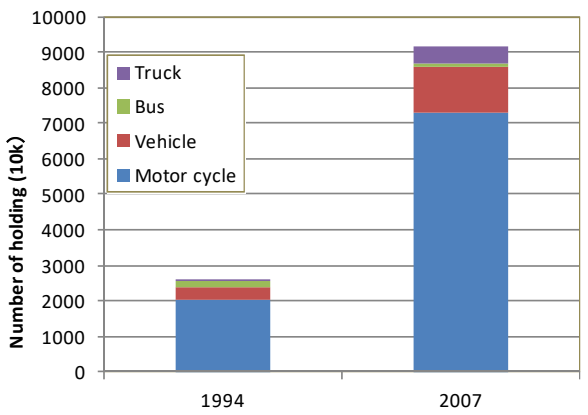

(b) Number of Vehicle in Road Transportation

Figure 2. India Road Transportation

The majority of share of transportation is motorcycle and this situation is still same at period 2020. This trend is common in any other developing countries.

In this study, it is necessary to visualize actual traffic condition with measurement data and understand traffic flow with transportation parameters. Author has a chance to have Japanese and Indian government project focused on study of urban transportation analysis in India since April 2017 [3]. In terms of research of traffic flow, there are several studies [4, 5]. And as for Indian traffic research, there are also several studies else these days. For example, A.Salim et al. has analysis traffic congestion by using traffic density and space headway parameter [6] but the measurement is only four days in Chennai in India. And M.Goutham and B.Chanda shows vehicle probe data in terms of traffic service by traffic volume and speed in Hyderabad of India based on Indian Road Standard IRC-106-1990 [7]. Here we have multiple month measurement analysis from January 2019 to August 2019 in Ahmedabad city of Gujarat state in India. This is the first time to make such long span period of traffic measurement analysis, especially in India.

In the next section 2, it describes the traffic flow theory and measurement. Then it is introduced traffic flow analysis in section2. As for traffic congestion and spatial analysis, it is described in section 3. The discussion is in section 4 and conclusion is followed in section 5 .

\section{Theory and Measurements}

\subsection{Traffic Flow Theory}

The traffic flow theory has long history from 1930s. The famous theory is known as Greenshields observation model which is firstly shown to the public exactly 75 years ago (Proc. of the 13th Annual Meeting of the Highway Research Board, Dec. 1933) [8].

Greenshields equation is given by Equation (1).

$$
v=v_{f}\left(1-\frac{k}{k_{j}}\right)
$$

where $v_{f}$ is free speed, $k_{j}$ is jam traffic density.

In traffic flow contiguous characteristics, Equation (2) is given.

$$
q=k \times v
$$

where $q$ is traffic volume, $v$ is vehicle speed.

From Equation (1) and (3), Equation (3) is taken.

$$
q=v_{f}\left(1-\frac{k}{k_{j}}\right) k
$$

Then Equation (4) is taken by transforming Equation (3). 


$$
q=-\frac{v_{f}}{k_{j}}\left(k-\frac{k_{j}}{2}\right)^{2}+\frac{v_{f} k_{j}}{4}
$$

From the above traffic flow theory, three fundamental traffic flow characteristics illustration are shown in Figure 3 and traffic congestion point is marked in each graph. The traffic congestion is occurred in high traffic density area and traffic volume has critical value where is a threshold point between no congestion and congestion point.

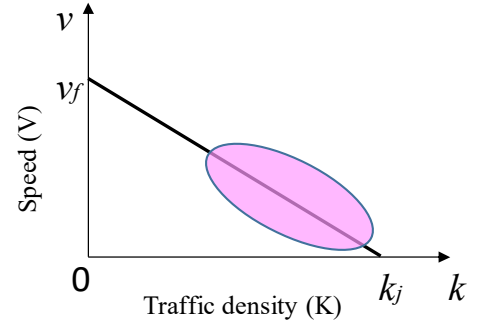

(a) k-v curve

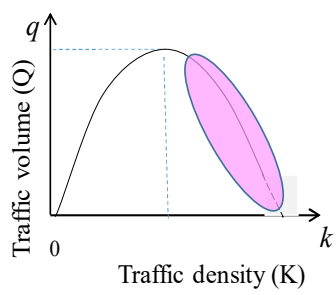

(b) k-q curve

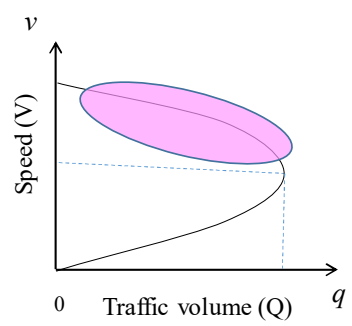

(c) q-v curve

Figure 3. Theoretical Fundamental Traffic Flow Characteristics

\subsection{Traffic Flow Measurements}

\subsubsection{Measurement Environment}

The project which author has been involved is so call "SATREPS" project or Science and Technology Research Partnership for Sustainable Development [9] and it focuses on Low Carbon Urban Transportation development. Under this project, we installed traffic monitoring cameras CCTVs) and used traffic sign board which provided real time traffic condition and was called VMS or Variable Message Sign in Ahmedabad city. Ahmedabad city has about 8 million population [10] and the number of four wheelers is 2.6 million, that of two wheelers is 15.8 million in 2018 [11]. The four wheelers growth rate is 65\% compared with in 2010. And Ahmedabad is an economic and industrial hub of India and is the largest city in Gujarat stat. Therefore there are heavy traffic congestion and local government Ahmedabad Municipal Corporation faces sever condition for urban transportation management. We took 21 CCTVs out of total 35 CCTVs (CCTV No.1 is currently removed) in the city and each location is shown in Figure 4. In Figure 4, the number is CCTV number which is used for collecting traffic flow data i.e. number of vehicles, average vehicle speed, gap or headway between vehicles, vehicle length etc. All traffic flow data is measured every minute. The volume of the measurement data becomes 43,200 points per location for one month. In this study, we use 8 months data from January to August 2019.

As shown in Figure 4, there are three segments for traffic data measurement. The left side of group is along major road 132 Feet Ring Road (CCTV number is from 2 to 14). In this area, there are new shopping mall, restaurants and business offices (CCTV number is from 1001 to 1018). The second group is near the river area-Sabarmati Riverfront. The third group is major junction-Paldi Junction, which is the end point of Flyover starting from near CCTV No.11. In Ahmedabad, there is under construction of Metro which is consisted with North-South line and East-West line. Metro service has been started partially from March 2019 and the phase 1 North-South line will be completed by 2023 [12]. In terms of public transportation, Ahmedabad has already dedicated bus raid transit service or BRT f0rm 2009 with $101 \mathrm{~km}$ operation and 275 buses [13]. 


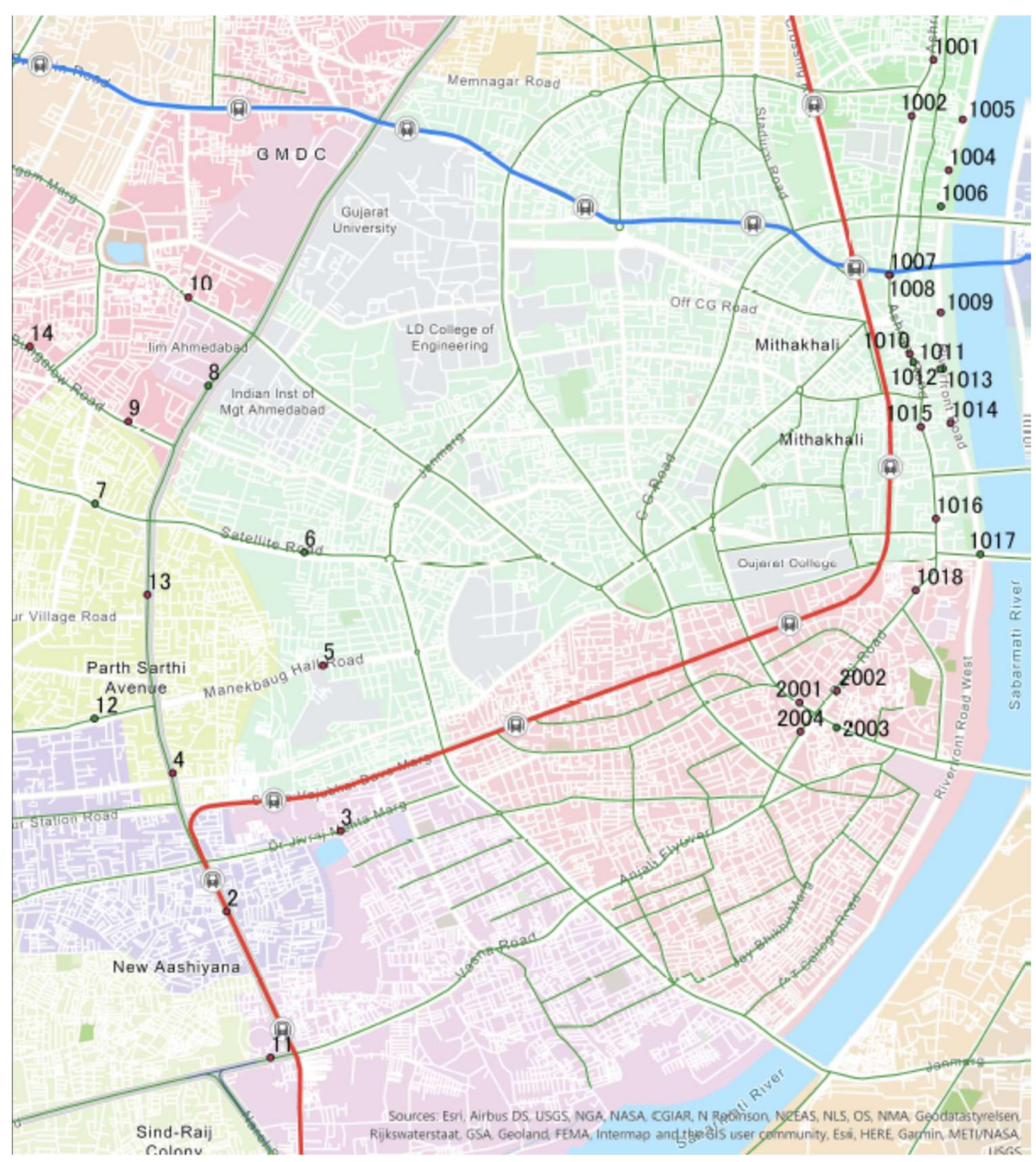

Figure 4. Traffic measurement Environment in Ahmedabad city.

\subsubsection{Traffic Data Measurement}

As the example of the fundamental traffic flow characteristics is shown in Figure 5 at CCTV No. 2 in June 2019. It is difficult to check its traffic congestion from these curve. The value of each graph is generalized by lane, for example $100 \mathrm{pcu} / \mathrm{km}$ traffic density means 100 vehicles $/ \mathrm{km}$-lane. The number of CCTV No.2 lane is two lanes (pcu: passenger car unit equals 1).

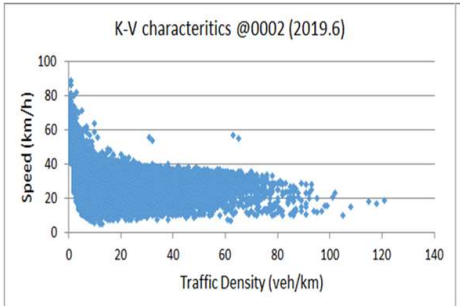

(a) k-v curve

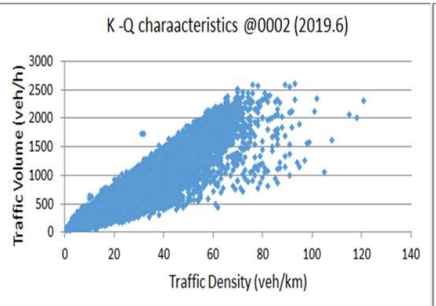

(b) k-q curve

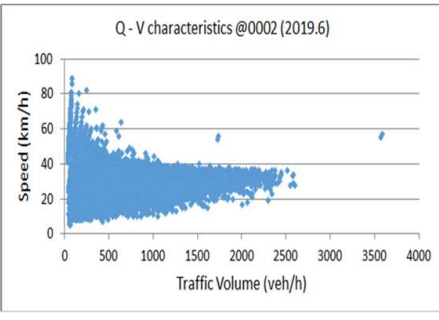

(c) q-v curve

Figure 5. Example of fundamental Traffic Flow Characteristics at CCTV no.2

When traffic condition is shown time base, traffic volume and average vehicle speed graph are shown in Figure 6. From Figure 6, there are two traffic volume peaks in the morning and evening. 
And it is clear about traffic congestion from their vehicle speed. The traffic speed in the evening is lower than that of morning, which means evening traffic congestion is heavier than in the morning. Those traffic flow characteristics trend at other location is similar.

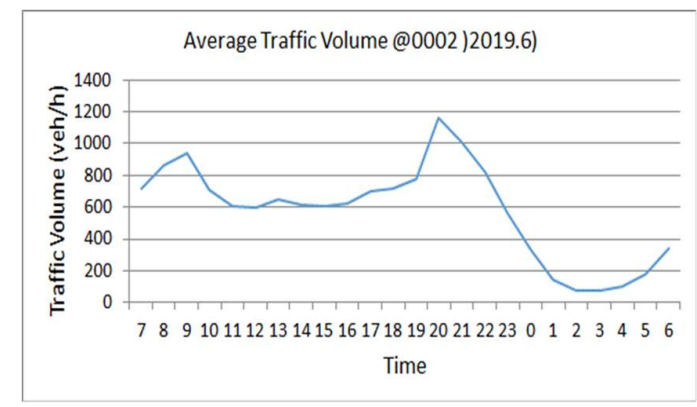

(a) Traffic Volume

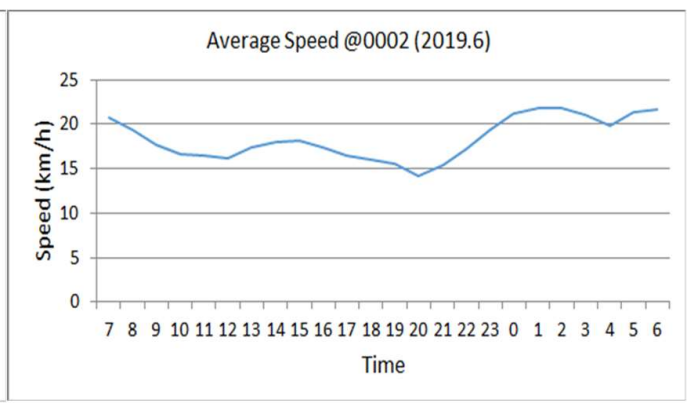

(b) Vehicle Speed

Figure 6. Example of daily Traffic Flow Characteristics at CCVT No.2

In general, there is a parameter which shows traffic congestion-Occupancy (OC) - which is defined the percentage ratio between total measurement time $(t)$ of the vehicles to a certain block of road section under certain moment shown as Equation (5).

$$
O C=\frac{1}{T} \sum_{i} t_{i} \times 100(\%)
$$

where $T$ is time of measurement, ti is detected time of vehicle $i$ [14].

When number of existing vehicle a certain section is $N$, average length of vehicle is $\bar{l}$, Equation (6) is given.

$$
O C=100 \frac{q}{v} \bar{l}=100 k \bar{l}
$$

Therefore occupancy $(O C)$ is proportional to traffic density $(k)$ and traffic volume $(q)$.

Figure 7 shows an example of traffic volume $(q)$, travel time $(1 / v)$, and occupancy $(O C)$ of CCTV No.2 in June 2019. From Figure 7, it is explicit that occupancy presents its traffic congestion. Compared with the result of Figure 6. Therefor it is focused on occupancy from the next section for traffic congestion analysis.

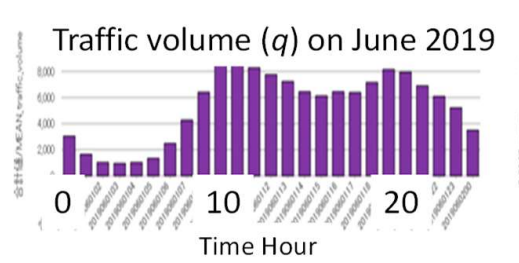

(a) Daily Traffic Volume

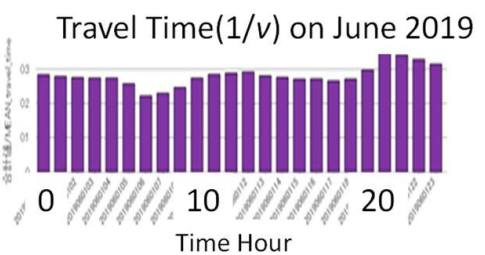

(b) Daily Travel Time

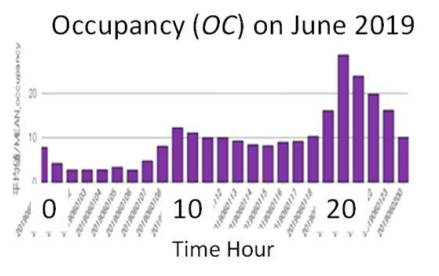

(c) Daily Occupancy

Figure 7. Daily Traffic Flow Measurement Data at CCTV No.2

\section{Congestion Analysis}

\subsection{Congestion Time Analysis}

In this section, it is introduced about multiple month and multiple location traffic data observation and discussed about traffic congestion in the city. In Figure 8, it shows traffic occupancy in all measurement points in Ahmedabad city. In additionally, it shows heat-map for monthly to day 
base and weekly to hour base occupancy level in measurement points in Figure 9. From the both Figure 8 and 9, the following points are clear from these observation.

- $\quad$ The congestion pattern during 8 month is similar (Figure 8)

- May is relatively not congested because of summer vacation season (Figure 9)

- $\quad$ The congestion pattern from Monday through Saturday is similar (Figure 9)

- $\quad$ The most congested time frame is in the evening from 19:00 to 21:00 (Figure 9)

- The Saturdays are slightly different with other week day traffic condition because it is half day working in India

The occupancy value level difference between Figure (a) and (b), which is caused by rounding number for each period (per month and week).

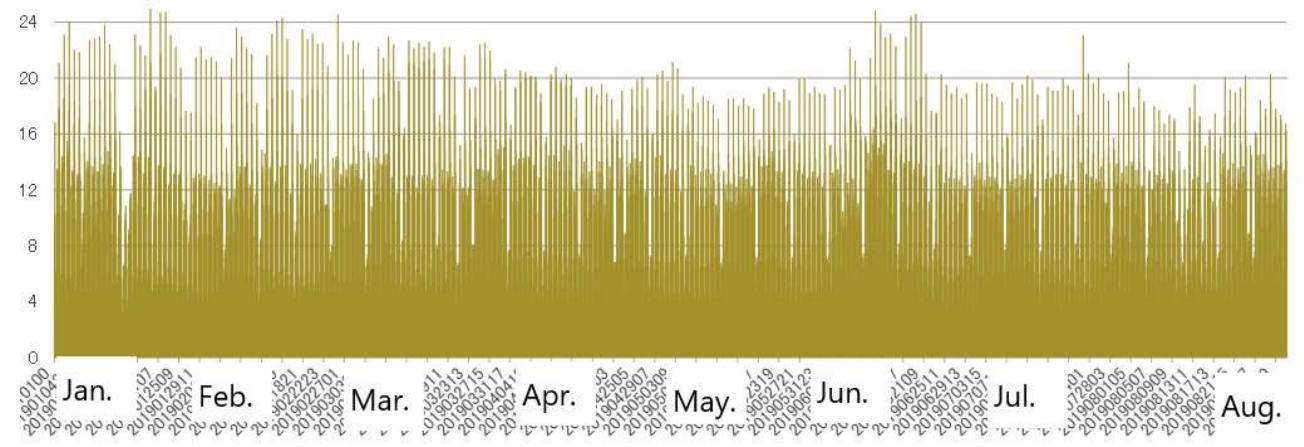

Figure 8. Average Occupancy in Ahmedabad from January to August 2019

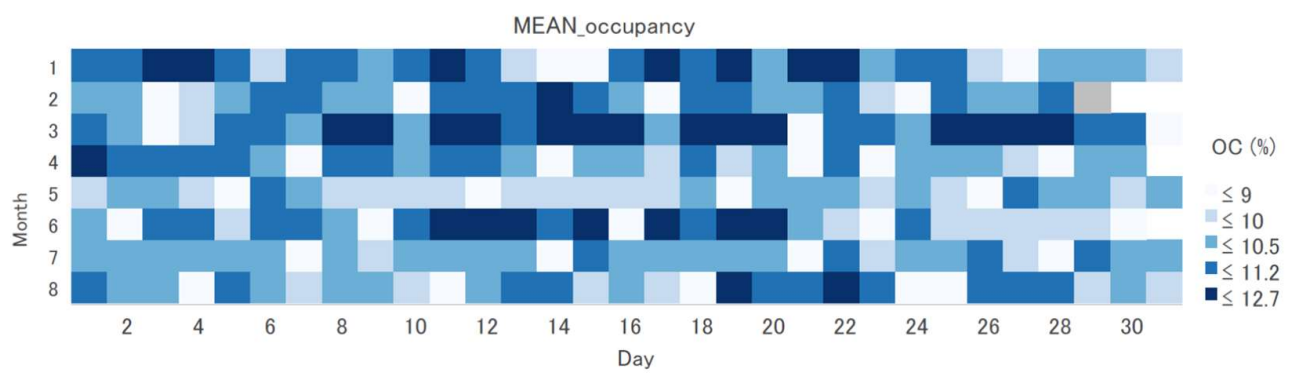

(a) Monthly Occupancy Heat map

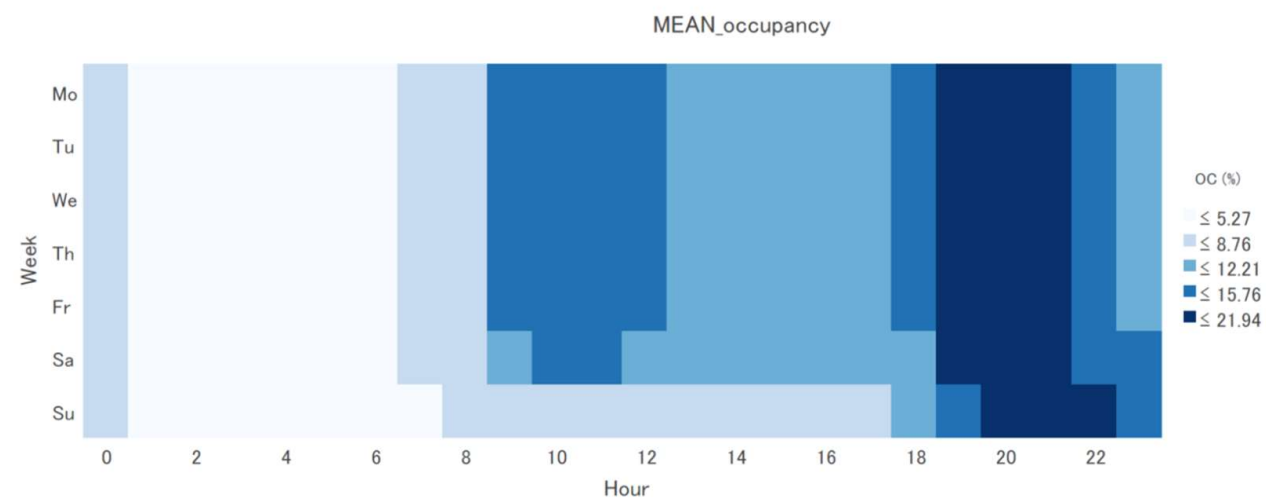

(b) Weekly Occupancy Heat map

Figure 9. Monthly and Weekly base Occupancy Trend in Ahmedabad 


\subsection{Congestion Spatial Analysis}

In this section, it focuses on spatial congestion in case of particular day time. Let's take the day when it is $26^{\text {th }}$ of April in 2019 for example. The occupancy value in the city on $26^{\text {th }}$ of June 2019 is shown in Figure 10. In this one day occupancy observation, it picks up some data example study for spatial analysis, for example four time zone is (a) 10:00-10:59, (b) 13:00-13:59, (c) 18:00-18:59 and (d) 20:00-20:59. Before starting spatial analysis, it takes traffic volume comparison on $26^{\text {th }}$ of April and it shows daily traffic volume in Figure 11. The comparison between occupancy and traffic volume brings that traffic volume does not always show traffic congestion condition. The maximum of traffic volume happens in (a) 10:00-10:59 time zone and second traffic volume does in (d) 20:00-20:59 time zone. On the other hand, the occupancy is maximum in (d) 20:00-20:59 time zone and the second is in (a) 10:00-10:59 time zone. This is important feature in Ahmedabad city traffic condition. This is same situation in each CCTV location such as in Figure 7.

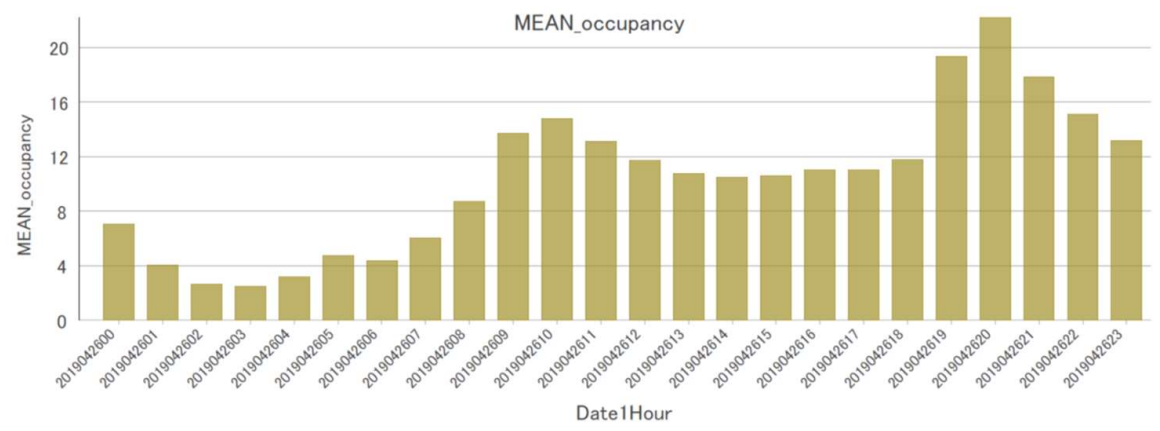

Figure 10. One day Occupancy in Ahmedabad (26 $6^{\text {th }}$ of April 2019)

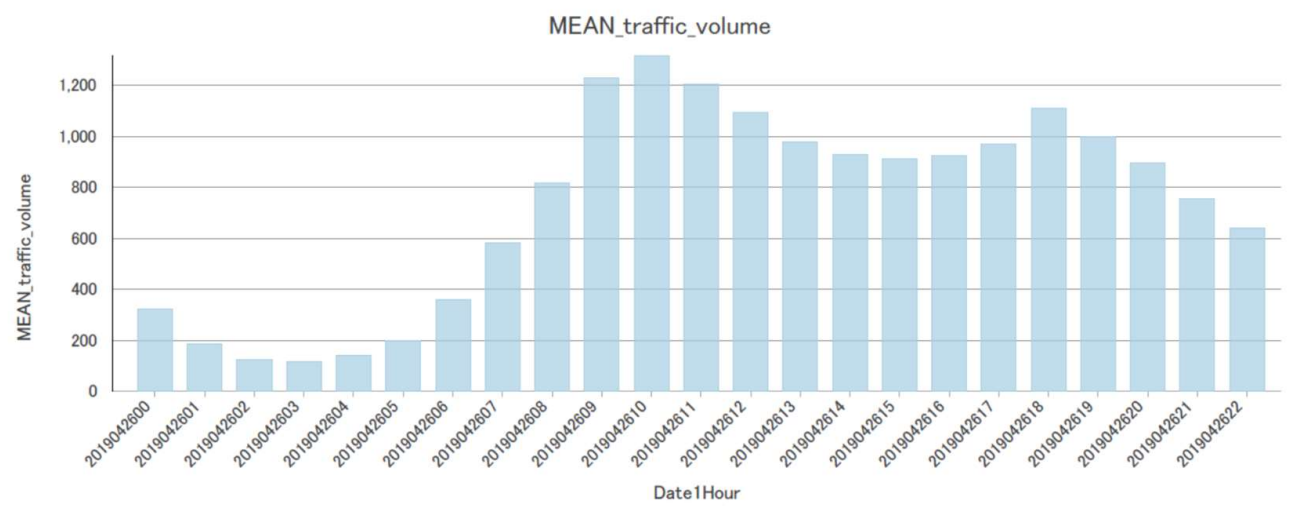

Figure 11. One-day Traffic Volume in Ahmedabad (26 $6^{\text {th }}$ of April 2019)

In Figure 12, spatial occupancy of each time zone is shown, which dark color is large value of occupancy, of which range of from $0 \%$ to $60 \%$. . From Figure 11, the following points are able to see as Ahmedabad traffic congestion features;

- There are two traffic congestion in the city Figure 12 (a) and (d)

- The congested points are identical in the city

- The most congestion condition occurs in the evening Figure 12 (d)

- The most congested point is near CCTV No.2 area

In terms of spatial analysis, it is used inverse distance weight (IDW) extrapolation among measurement points. Therefor occupancy or congestion spatial level does not present the real traffic 
congestion condition. In case of detail congestion analysis, it is necessary to compare with all related road measurement. The GIS tool in this research is used ArcGIS and ArcGIS Pro from Esri (Environmental Systems Research Institute) product.

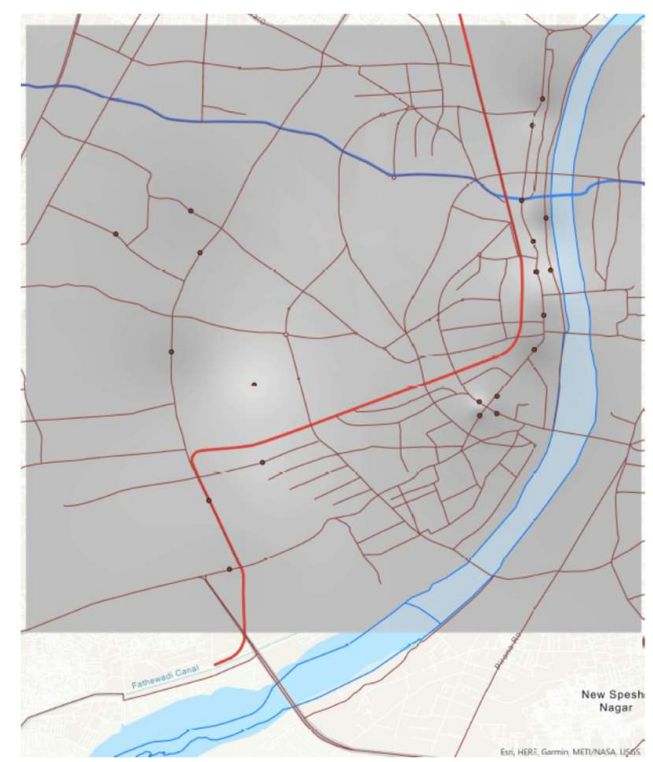

(a) Occupancy level at 10:00-10:59

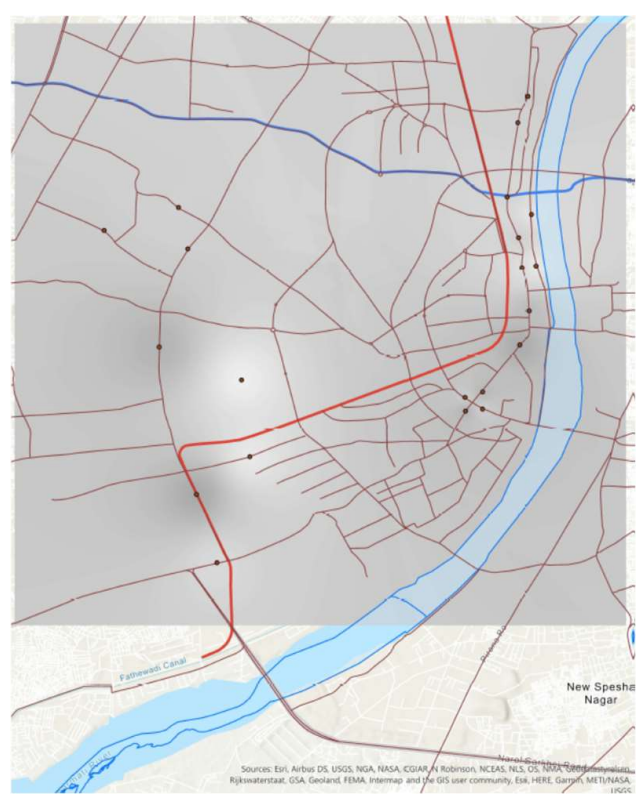

(c) Occupancy level at 18:00-18:59

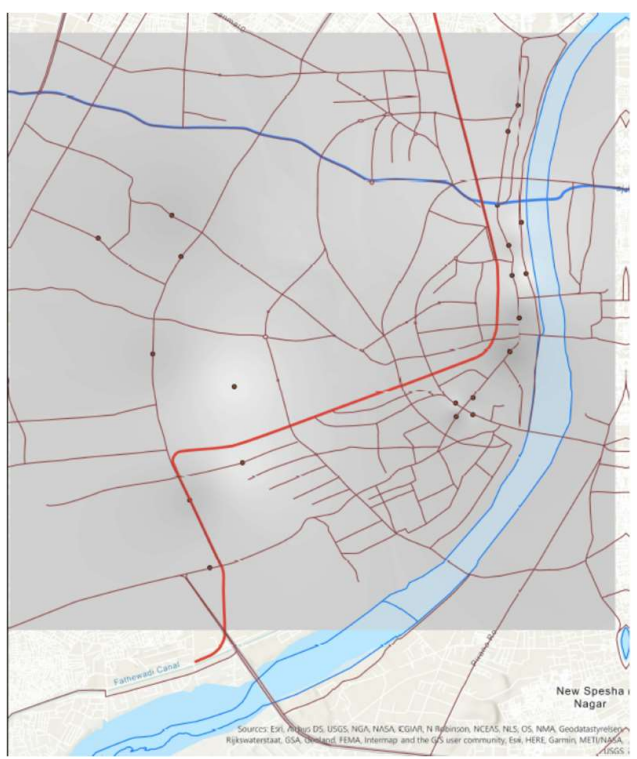

(b) Occupancy level at 13:00-13:59

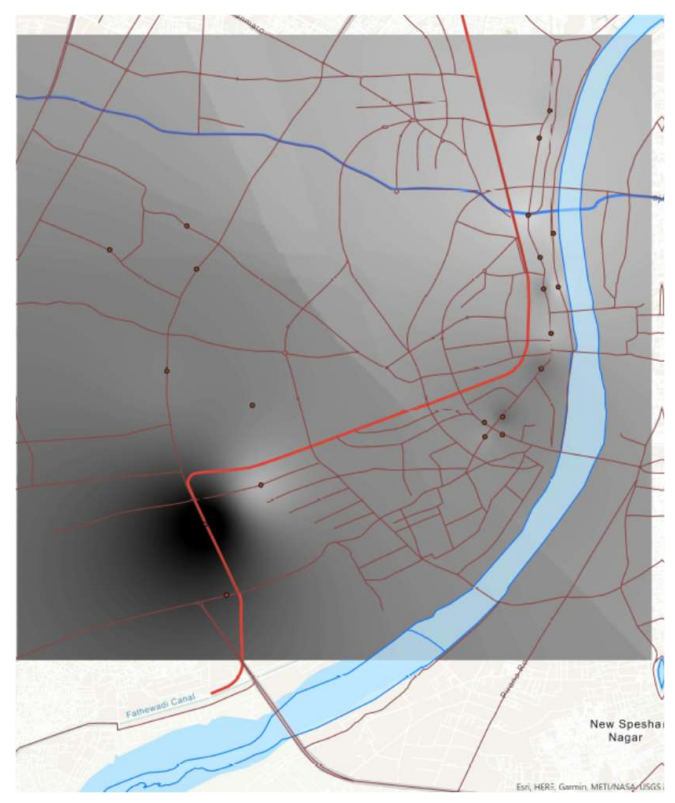

(d) Occupancy level at 20:00-2059

Figure 12. Congestion Spatial by time zone basis Analysis

\section{Discussion}

In general, it is told that the traffic congestion is always issue in the developing countries and it is difficult to manage reduction and or improvement of traffic condition. In this study, author finds some trend of daily traffic congestion by 8 months traffic data observation in Ahmedabad city in India. In this study, we focus on traffic occupancy parameter as indicator of traffic congestion rather than traffic volume. From Figure 6 and 7 at CCTV No.2 data, traffic volume does not always show traffic congestion. But occupancy is able to show more real traffic congestion condition. The traffic 
volume in the morning is larger than that of in the evening.at CCTV No.2 of June 2019 but traffic congestion in the evening is more than that of in the morning based on average vehicle speed.

In terms of relationship between traffic volume and occupancy, it is shown from total 8 month data in Figure 13. There are wide spread between traffic volume and occupancy but the shape of boundary looks triangle. In author's previous research [15], we found there are two type of traffic congestion i.e. high volume and light congestion in the morning (AM congestion) and low volume and heavy congestion in the evening (PM congestion). The AM congestion line is lower boundary of Figure 12 and PM congestion is higher boundary in Figure 13 As the result, occupancy is most representation of traffic congestion. As the reference, Figure 14 shows CCTV No.3 on June 2015 [15] and number of Figure 14 represents each time zone. From Figure 14, it is clear about AM congestion and PM congestion positioning.

As we see in section 3, we make Indian traffic condition visible by Congestion Time Analysis and Congestion Spatial Analysis and get understanding of those. It is interesting point which the most traffic congestion occurs in the evening time in Ahmedabad and its location is almost same position near CCTV No.2 point. The CCTV No.2 is located at the starting point of 132 Feet Ring Road and there are many restaurants, shops, and business office. And this point is also located towards Flyover which is newly opened along the right direction or road which goes to the river side. So there is some reason for traffic congestion. It should be study item in future. It is also necessary to continue collecting data in whole year. We also have special data under COVID-19 situation, so it will be analyzed in next study.

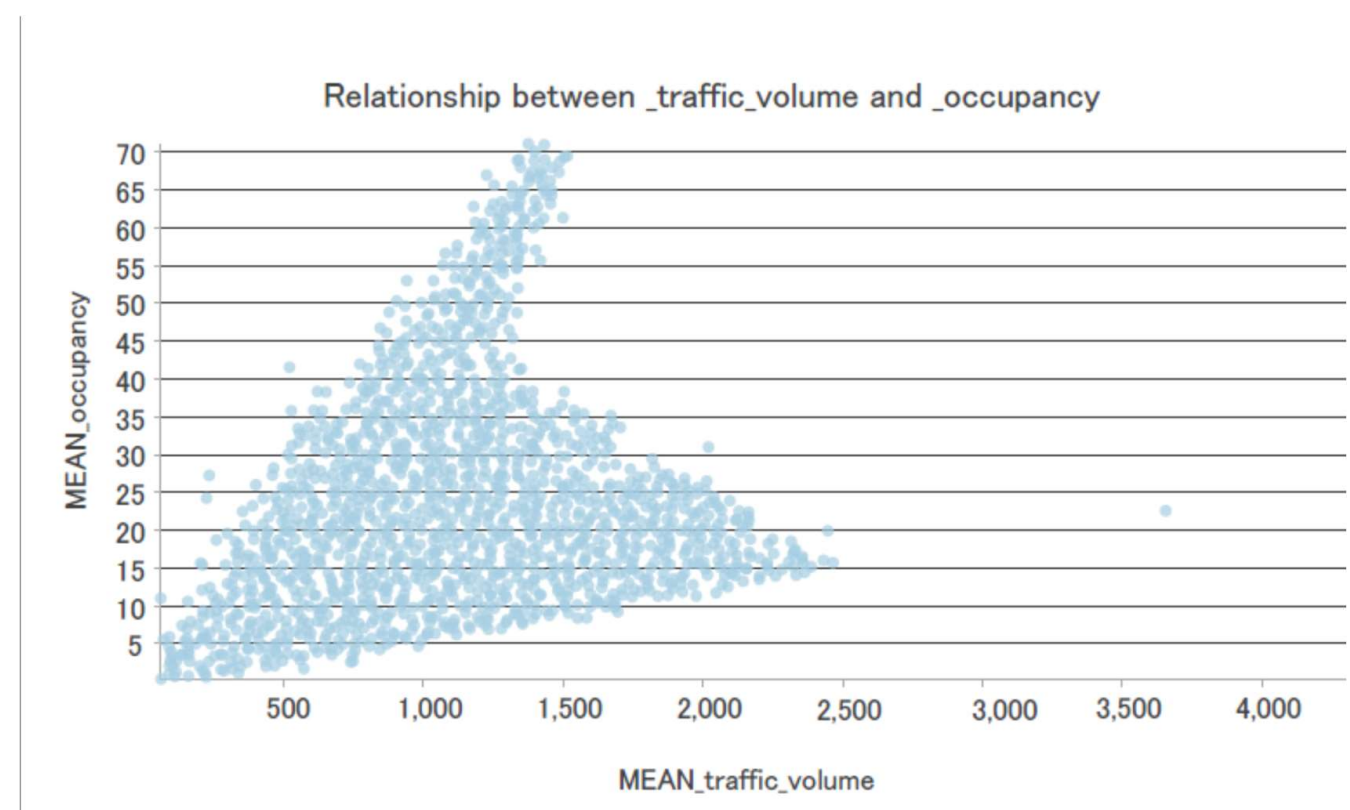

Figure 13. The Relationship between traffic volumes to occupancy in Ahmedabad 


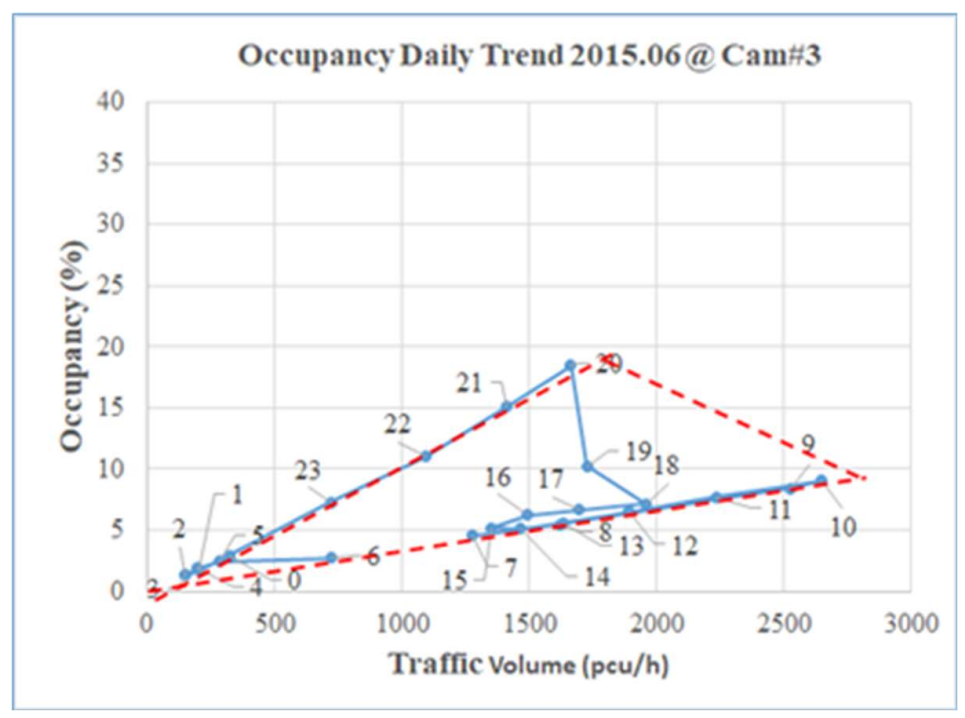

Figure 14. Relationship example of CCTV No.3 in June 2015

\section{Conclusions}

We have succeeded to make visualization of actual traffic condition and got some understanding about traffic congestion in Ahmedabad by using traffic flow and GIS tools with 8 month traffic data. The traffic congestion is able to get from occupancy parameter and it is better indication rather than its traffic volume monitoring. And in Ahmedabad city, the traffic congestion occurs in the evening from 19:00 to 21:00 and particular location. This means there are some reason for Ahmedabad traffic congestion. The detail study has to be done in future study. And Ahmedabad traffic congestion is not always happened which means there is solution for traffic congestion reduction. This is good hints for other developing countries traffic studies.

Acknowledgments: The Japan Traffic Management Technology Association, who has been provide about the data used in the current simulation, will be aware of the feeling of the public interest. This study also underwent the Program ID JPMJSA1606 of the International Science and Technology Cooperation Program (SATREPS) challenges for global challenges in 2016.

Conflicts of Interest: There is no conflict of interest. In this study.. 


\section{References}

1. R.K.Pachauri, L.Meyer, The Core Writing Team, Climate Change 2014 Synthesis Report, IPCC, $2014 ;$ p.47.

2. A. Anil Singh, India: Transportation Sector Greenhouse Gas Emissions 2007, Indo-US workshop, 2011.02.11, CRRI.

3. T.Tsuboi, Quantitative Traffic Congestion Analysis Approach in Ahmedabad, Advances in Science, Technology and Engineering Systems Journal Vol. 4, No. 3, 2019, pp.183-189.

4. N.Gartner, C.J. Messer,A.K.Rathi, Traffic Flow Theory A State-of-the-Art Report: Committee on Traffic Flow Theory and Characteristics (AHB45) , 2001.

5. C. Millikarjuna, K.R.Rao, Area occupancy characteristics of heterogeneous traffic, Journal Transportmetrica Volume 2, Issue 3, 2006.

6. A.Salim, L.Vanajakshi, C.Subramanian, Estimation of Average Space Headway under Heterogeneous Traffic Conditions, International of Recent Trends in Engineering and Technology, Vol. 3, No.5, 2010.

7. M.Goutham and B.Chanda, Introduction to the selection of corridor and requirement, implementation of IHVS (Intelligent Vehicle Highway System) In Hyderabad, International Journal of Modern Engineering Research, Vol.4, Iss.7, 2014, pp.49-54..

8. [B. D. Greenshields, A Study of Traffic Capaci, Proc.H.R.B., 14, 1933, pp.448-477.

9. Japan Science and Technology Agency, (Available web site; https://www.jst.go.jp/global/english/about.html).

10. Ahmedabad Municipal Corporation official website information: https://ahmedabadcity.gov.in/portal/jsp/Static_pages/demographics.jsp.

11. Commissionerate of Transport Department of Port and Transport, Government of Gujrat data at http://rtogujarat.gov.in/statistics_vehicle.php.

12. Gujarat Metro Railway Corporation (GMRC) Limited. (available web site; https://www.gujaratmetrorail.com/)

13. Ahmedabad Janmarg Limited. (available web site; http://125.17.144.54:8082/)

14. S.Kawakami, H.Matsui, Transport Engineering, Morikita Publishing Co., 2007 pp.102-103

15. T.Tsuboi, "Traffic Congestion Triangle" based on more than one-month real traffic big data analysis in India, $2^{\text {nd }}$ International Virtual Conference on Multidisciplinary Research 2020. 